\title{
O Papel do Professor na Percepção dos Alunos de Odontologia'
}

\section{The Role of the Teacher According to the Perceptions of Dentistry Students'}

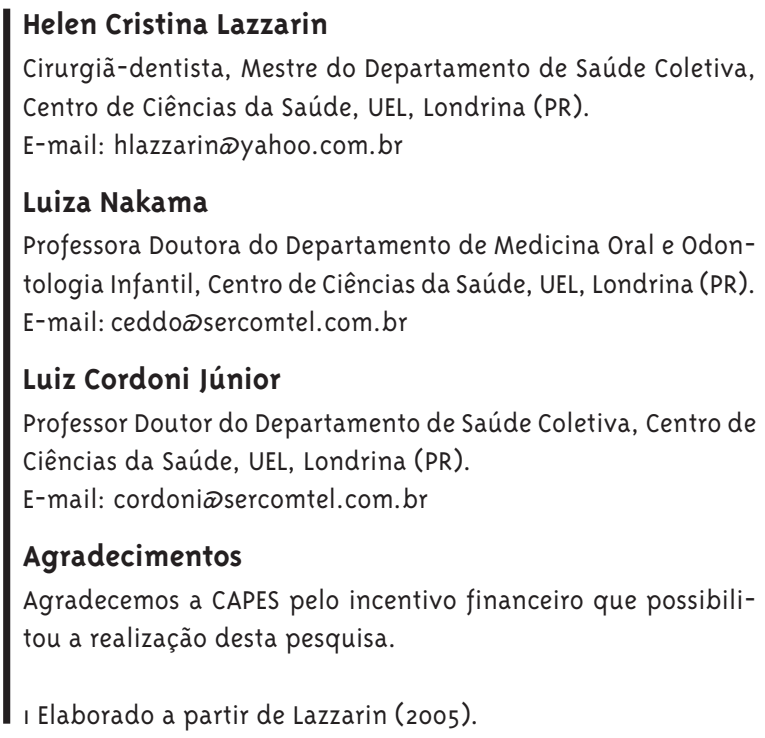

I Elaborado a partir de Lazzarin (2005).

\section{Resumo}

É necessário que a qualidade das estratégias de ensino-aprendizagem utilizadas no ensino superior seja revista em decorrência das demandas da sociedade e da implantação das diretrizes curriculares nacionais. Neste contexto, analisamos a percepção de alunos do curso de graduação em odontologia da Universidade Estadual de Londrina a respeito do papel do professor no processo ensino-aprendizagem. Para isso, adotamos a abordagem qualitativa. A geração de dados ocorreu por meio de entrevista semi-estruturada. 0 estudo revelou que o professor tem papel fundamental no processo de ensino-aprendizagem. 0 ensino de graduação em odontologia pode ser compreendido como um sistema formador de profissionais para o mercado de trabalho; as estratégias de ensino-aprendizagem baseiam-se em exposições orais, e o método de avaliação consta de provas tradicionais teóricas e práticas. Podemos concluir, portanto, que há uma necessidade de mudanças na graduação do cirurgião-dentista para que seja possível formar os profissionais de forma generalista, humanista, crítica e reflexiva.

Palavras-chave: Educação em odontologia/métodos; Docentes de odontologia; Educação superior; Estudantes de odontologia; Currículo. 


\section{Abstract}

Higher Education teaching and learning strategies must be revised due to the demands of a dynamic society and to the implementation of national curricular guidelines. Within this context, we analyzed the perceptions of dentistry undergraduate students of Universidade Estadual de Londrina regarding the role of the teacher in the teaching and learning process. A qualitative research was carried out, and data were collected through semi-structured interviews. Results showed that the teacher plays an essential role in the teaching and learning process. Undergraduate education in dentistry can be defined as a liberal professional educational system; teaching and learning strategies are based on the oral transmission of information, and evaluation is carried out through theoretical and practical traditional tests. In conclusion, findings from this study have shown the need of changes in the undergraduate level, so that dentistry professionals can be educated in a general, humanist, critical and reflexive way.

Keywords: Dental Education/Methods; Dental Faculty; Higher Education; Dental Students; Curriculum.

\section{Introdução}

Tem sido dada grande ênfase às questões que cercam o processo de ensino-aprendizagem no ensino superior com relação à qualidade das práticas pedagógicas que se desenvolvem no interior das instituições de ensino superior (IES), em decorrência das demandas da sociedade, considerando os cursos de odontologia (Raldi e col., 2003). Delors (2001) constata que há uma crise no ensino superior em grande parte do mundo em desenvolvimento que determina a necessidade de reforma da educação.

A Organização das Nações Unidas para a Educação, Ciência e a Cultura (Unesco) designou uma comissão para estabelecer diretrizes para a educação mundial no século XXI, a qual gerou o Relatório Delors. Dentre as recomendações da comissão, merece destaque a conformação dos quatro pilares da educação que, ao longo de toda a vida, serão de algum modo para cada indivíduo, os pilares do conhecimento: "aprender a conhecer, aprender a fazer, aprender a viver juntos, aprender a ser" (Delors, 2001, p.9o). Os quatro pilares devem constituir uma só via do saber.

Desde 1996, quando foi promulgada a nova Lei de Diretrizes e Bases da Educação Nacional (LDB), o Ministério da Educação (MEC) tem conduzido discussões sobre o processo de formação de profissionais de diferentes áreas, por meio das Diretrizes Curriculares Nacionais (DCN). As diretrizes devem ser necessariamente respeitadas por todas as IES, porém admitem certa flexibilidade visando à qualidade da formação oferecida aos estudantes (Brasil, 1997). Para Feuerwerker (2003), as propostas de mudança na formação dos profissionais de saúde norteadas pelas novas diretrizes curriculares estão orientadas à superação de alguns problemas que estão ocorrendo nas universidades, como a insuficiente produção de conhecimento e os problemas na formação profissional marcados pela especialização, pela fragmentação e pelos interesses econômicos.

Após a reforma universitária de 1968, com a implementação dos cursos de pós-graduação e as exigências de titulação para a carreira universitária (Carvalho, 1995), teve início o questionamento a respeito da atuação docente daqueles que não receberam o mínimo de formação pedagógica e, como decorrência disso, apresentam dificuldades no exercício desta atividade (Carvalho, 1998). 
Para melhorar a qualidade da educação no ensino superior é preciso investigar os cursos superiores de formação profissional, pois, os estudos sobre pedagogia universitária são escassos.

Como em qualquer curso superior, a qualidade do ensino de odontologia está relacionada a um adequado modelo pedagógico da universidade e do curso. Além disso, a qualificação e a atualização permanente (tanto técnica quanto didático-pedagógica) do corpo docente são essenciais para proporcionar uma formação generalista, humanista, crítica e reflexiva.

Os trabalhos a respeito da qualificação dos cursos de odontologia são escassos; os que existem apontam inadequações, como o alheamento dos cursos em relação aos problemas comunitários; a preocupação em elevar cada vez mais o nível de sofisticação dos procedimentos técnicos a serem incorporados à formação do profissional; o planejamento curricular feito a partir dos pontos de vista dominantes entre o corpo docente, sem preocupação com produto final; a crise do modelo pedagógico com programas desenvolvidos por disciplinas e aprendizagem predominantemente psicomotora, devido à sua determinância tecnicista; o isolamento profissional, impedindo as relações da odontologia com as demais profissões de saúde; a prestação de serviços como instrumento de ensino; e a formação do cirurgião-dentista com caráter mercadológico (Botazzo, 20oo; Chaves, 1986; Narvai, 2001).

Este trabalho teve como objetivo analisar a percepção de alunos do curso de graduação em odontologia da Universidade Estadual de Londrina a respeito do papel do professor cirurgião-dentista no processo ensino-aprendizagem. Essas percepções podem contribuir para a formulação de um projeto de formação didático-pedagógica do docente de odontologia que vise à mudança do perfil do egresso.

\section{Metodologia}

Adotamos a abordagem qualitativa para responder às questões dinâmicas e complexas propostas pela pesquisa educacional, visto que a pesquisa qualitativa responde a questões muito particulares (Lüdke e André, 1986) e é importante para compreender as relações entre atores sociais e sua situação (Minayo, 1994).

Investigar o papel do professor no processo de en- sino-aprendizagem em um curso de graduação em odontologia implica em explorar as percepções experimentadas pelos alunos deste curso. Assim, foram entrevistados os alunos do quinto ano do curso de graduação em Odontologia da Universidade Estadual de Londrina (UEL), entendendo que os formandos estão mais aptos a discorrer sobre seu processo de formação acadêmica por terem passado por todos os estágios educacionais e por terem tido contato com um número mais amplo de docentes durante o curso.

Houve um contato prévio com os possíveis entrevistados para explicar-lhes os objetivos da investigação, solicitar-lhes a colaboração e agendar as entrevistas, sendo incluídos no estudo os que concordaram em participar da pesquisa e os que tiveram disponibilidade de tempo e facilidade de contato (Turato, 2003).

Os dados foram obtidos por meio de entrevista semi-estruturada com 10 alunos, de ambos os sexos, com idades entre 22 e 28 anos, realizadas no período de novembro de 2004 a dezembro de 2004. As entrevistas foram encerradas quando se verificou que a inclusão de novos estratos passou a apresentar uma quantidade de repetições em seu conteúdo - critério de saturação (Turato, 2003).

As entrevistas foram gravadas e posteriormente transcritas. Os dados foram analisados por meio da análise de conteúdo temática (Bardin, 1977), com o auxílio do programa N-Vivo versão 1.2 (Fraser, 200o). Os alunos entrevistados foram identificados letra A (aluno). Assim, A2 refere-se à segunda entrevista do grupo de alunos.

A partir das entrevistas realizadas foram identificadas as seguintes categorias de análise associadas à percepção de alunos de odontologia quanto ao papel do professor no processo ensino-aprendizagem: papel do professor; influência do professor na aprendizagem; conteúdos curriculares e imagem-objetivo da profissão; estratégias de ensino-aprendizagem; avaliação.

Vale ressaltar que este artigo é parte de uma pesquisa mais ampla (Lazzarin, 2005) que envolveu entrevistas com professores e alunos do curso de graduação em odontologia. Os dados aqui analisados referem-se apenas às percepções dos alunos.

0 projeto da pesquisa foi aprovado pelo Comitê de Ética em Pesquisa da UEL (parecer nº 204/o4). 


\section{Resultados e Discussão}

\section{Papel do professor}

Sobre o papel do professor na formação de graduação do cirurgião-dentista, os alunos entrevistados enfatizaram que o docente tem papel fundamental no processo de ensino-aprendizagem, sendo considerado responsável pela transmissão de conhecimentos e de experiências. Além disso, o papel do professor foi apontado como o de ensinar, de orientar e tirar dúvidas, tanto na teoria quanto na prática, e também como o de avaliar o aluno:

O papel da formação do profissional seria na transmissão do conhecimento, na avaliação do aluno durante o curso, avaliação do aluno durante o procedimento em caso de dúvidas (...). (A1)

[O professor] ensina passando os conhecimentos que ele tem, às vezes, mais de experiência clínica do que de conceitos de livros (...). (A7)

Sem professor seria meio difícil a gente saber como lidar com certas coisas, algum tipo de procedimento que a gente não tenha visto na teoria. Na clínica é muito importante pra ajudar a gente, alguma dúvida que a gente tenha. (A7)

Esses relatos deixam claro que existe uma grande ênfase no processo de ensino centrado no professor, que aparece como agente principal e responsável pelo ensino, e uma quase omissão em relação ao processo de aprendizagem. Pode-se dizer que o trabalho docente é uma atividade predefinida fora da escola, pois, a educação serve aos interesses de uma sociedade historicamente situada. Assim, a maneira de ensinar e o que cada professor ensina estão dentro de princípios predefinidos socialmente.

De acordo com Cunha (1998), a forte presença do paradigma da ciência moderna na sociedade ocidental favoreceu a forma tradicional de currículo, segundo a qual espera-se que o professor de ensino superior seja a principal fonte do conhecimento, além de apresentar as informações fidedignas e organizadas. Esse paradigma foi construído sobre o conceito de racionalidade, com o intuito de dominar a natureza, subjugá-la ao ser humano, negando o pensamento dominante até o renascimento, de que a fé e a natureza eram as grandes forças universais. As conseqüências do modernismo científico favoreceram o desenvolvimen- to da civilização européia que ganhou poder para conquistar o mundo, fazendo surgir novos valores e objetivos. Expandiram-se o comércio e as conquistas, e o trabalho humano começou a ser medido em termos de produtividade. Essa racionalidade presidiu e ainda preside a concepção epistemológica do pensamento convergente e a pedagogia da resposta única, que não desafia os alunos com questões significativas, tornando a educação trivial, quase um rito insignificante de passagem para a vida adulta.

A predominância da exposição oral é compreensível no contexto atual do ensino de odontologia marcado pela pedagogia tradicional. Segundo Libâneo (1992), os indivíduos são preparados para desempenhar papéis sociais, adaptando-se aos valores e às normas vigentes na sociedade de classes. Os conteúdos são separados da experiência do aluno e das realidades sociais. $\mathrm{O}$ aluno recebe pacientemente, memoriza e repete as informações transmitidas pelo professor visando disciplinar a mente e formar hábitos. No relacionamento professor-aluno predomina a autoridade do professor que exige receptividade dos alunos e impede qualquer comunicação entre eles durante a aula.

Libâneo (1992) e Masetto (1998) colocam a aula expositiva como a mais tradicional das estratégias de ensino-aprendizagem, sendo a atividade mais empregada pelos professores. Além disso, a exposição é apontada como preferida pelos estudantes, que acham a posição de ouvinte confortável, principalmente se o professor torna a aula interessante, o que favorece a utilização dessa estratégia (Lemos, 2005).

Atualmente, nos cursos de graduação em odontologia os currículos possuem uma enorme carga horária, não havendo tempo para o estudo, o que resulta no repasse de conteúdos prontos e acabados, sem espaço para argumentação e dúvidas. Segundo Lemos (2005), os alunos resistem às atividades do pensamento, ou seja, aos questionamentos e à problematização, esperando encontrar professores que lhes transmitam certezas que sanem suas dúvidas para evitar o enfrentamento de dificuldades, riscos e frustrações, próprios da existência humana. Ao mesmo tempo, há uma desqualificação da teoria, pautada no princípio que o bom cirurgião-dentista é aquele que domina uma boa técnica. 
Segundo os entrevistados, o papel do professor é desenvolver valores pessoais e transmitir experiência: o papel do professor acho que mais do que passar a técnica e o conteúdo teórico é dar suporte ético, suporte de crescimento pessoal e exemplo, mais que tudo exemplo pra classe. Agora o ensinamento teórico, técnico isso a gente pode buscar mais em livros. (A1o)

Esse relato enfatiza o processo de aprendizagem, tendo o aluno como agente principal e responsável pela sua aprendizagem. É importante registrá-lo, embora os entrevistados tenham dado maior ênfase no processo de ensino centrado no professor. De acordo com Brasil (2002) e Masetto (1998), quando se dá ênfase ao processo de aprendizagem privilegia-se o crescimento e o desenvolvimento do aluno na sua totalidade, envolvendo as dimensões cognitivas, afetivas, psicomotoras nas áreas de formação geral, formação profissional e cidadania. Com relação à formação geral, devem-se buscar conhecimentos e atitudes relevantes para a formação científico-cultural do aluno. Quanto à formação profissional, devem-se procurar capacidades relativas às ocupações correspondentes. Quanto à cidadania, devem-se atingir atitudes e valores correspondentes à ética profissional e ao compromisso com a sociedade.

Também preocupados com a formação excessivamente técnica do curso de odontologia em detrimento à formação ética, Freitas e col. (2005) identificaram, a partir de entrevistas com 42 formandos de odontologia, os níveis de aplicação de valores morais universais trabalhados por eles diante de um problema concreto. Segundo esses autores, a maioria dos alunos entrevistados enquadrou-se em um nível de desenvolvimento moral que não reconhece direitos e deveres recíprocos em um sistema social e não tem preocupações pela coerência e imparcialidade de suas ações. De acordo com esses autores, 50\% dos formandos sustentam sua conduta profissional em ações individualistas, por medo de prejuízo pessoal ou de abalar sua reputação, agindo motivados pela troca de favores, não relativizando as situações do cotidiano. Essa constatação sugere uma evidente inadequação da maior parte dos cirurgiões-dentistas na prática da profissão, pautada por valores morais, em termos éticos e de responsabilidade social, comportamentos preocupantes, com conseqüências que podem ser graves para a sociedade.
Castanho (2002) ouviu professores do ensino superior da área de saúde sobre sua prática pedagógica cotidiana, visando encontrar eventuais marcas distintivas de sua docência. Foram entrevistados 11 professores, coordenadores, diretores, utilizando a metodologia da história oral temática. De acordo com os resultados, destacam-se: os professores que transmitiam o conhecimento, mas também davam "dicas" que iam além da questão técnica, formando profissionais completos e não apenas técnicos (grifo nosso); o professor com experiência e disponibilidade; professor que desenvolveu o hábito de estudar, de procurar, mostrando a responsabilidade pela educação continuada; o modo de dar aula de certos professores, a forma de fazer a parte prática, pelo conhecimento que tinha e que transmitia; o professor que era espelho de bom profissional, bom professor, pessoa competente; o professor que era bom educador, não ensinando apenas a matéria; o professor que sabia ensinar a postura necessária de vida em qualquer momento.

A escolha de professores marcantes que o aluno do ensino superior da área de saúde, em especial de odontologia, faz é baseada em sua prática social (grifo nosso), ou seja, o professor é valorizado principalmente pelo êxito que obtém no exercício de sua atividade como cirurgião-dentista. De acordo com Cunha e Leite (1996), essa imagem de sucesso é valorizada pelo docente, pois favorece sua atuação na área da profissão liberal. Os alunos estabelecem com o docente uma relação de admiração e dependência, incentivada pelo professor.

Um ponto importante a ser analisado, segundo Masetto (1998), é a forma como aprendem os alunos universitários. Eles podem ser tratados como adolescentes irresponsáveis com relação à formação profissional e, então, o professor assume a responsabilidade total pelo ensino, ou podem ser vistos como jovens iniciantes na vida profissional em processo de maturação, assim a aprendizagem será resultado de um trabalho cooperativo entre alunos e professor. No discurso de um discente entrevistado pôde-se observar a insegurança do aluno em relação à aprendizagem, necessitando que o professor assumisse a responsabilidade pelo ensino:

Eu acho que é extremamente fundamental o professor. Pelo menos eu preciso sempre que tenha alguém, porque não consigo estudar sozinha, por livros. Sempre tem que tá o professor orientando (...). (Ag) 
Nos diversos depoimentos, prevalece uma atitude passiva do aluno com relação aos professores, os quais são emissores de mensagens de diversos tipos, principalmente de conhecimentos e experiências, e os alunos são os receptores acríticos. Não se percebe uma construção do conhecimento, atitudes e habilidades como parceria entre ambas as partes. Percebe-se a construção como um produto coletivo, envolvendo outros atores, como os colegas, por exemplo, além do binômio professor-aluno.

\section{Influência do Professor na Aprendizagem}

Os entrevistados consideraram o professor, dependendo de suas atitudes, responsável pelo interesse e pelo desinteresse do aluno por determinada disciplina. De um lado, pôde-se observar que o professor atualizado e dedicado influencia positivamente na aprendizagem: Eu acho que [os professores] devem sempre tá se atualizando, procurando sempre passar melhores informações pro aluno (...), assim a gente se interessa mais pra procurar novas informações, se interessa mais pelas aulas. (A2)

Tem professor que tem boa vontade não mede esforços pra tá com a gente, faz o possível pra dar aula, ele se empenha mais (...), assim a gente pode aprender muito. (A2)

Por outro lado, a falta de interesse por parte do professor em se atualizar e em ensinar, de acordo com os entrevistados, influencia negativamente na aprendizagem dos alunos:

Grande parte dos professores influenciou no que eu aprendi por passar os conhecimentos pra mim corretamente, mas têm alguns [professores] que não fizeram muita diferença [na aprendizagem], porque não procuraram se aperfeiçoar, pararam no tempo, se acomodaram (...), às vezes, a gente até perde o interesse pela matéria. (A2)

(...) Alguns professores estão ali apenas cumprindo uma tarefa, fazendo placebo de professor, finge que ensina; nós alunos fingimos que aprendemos. (...) Quando nós temos professores que não dão a mínima se o aluno tá aprendendo ou não, conseqüentemente nós nos desinteressamos pela disciplina. (A6)

Delors (2001) e Rego (2001) também acreditam que o relacionamento professor-aluno tem um papel determinante na aprendizagem. Para Bordenave e Pereira (2002), o ensino consiste na resposta planejada às exigências naturais do processo de aprendizagem; é o resultado da relação pessoal do professor com o aluno. Logo, é possível que as atitudes positivas ou negativas dos professores exerçam efeito motivador ou desmotivador sobre os alunos, induzindo-os a alterar os seus níveis de esforço e empenhamento, com repercussões no desempenho acadêmico (Rego, 2001).

Raldi e col. (2003) verificaram por meio de um questionário, a opinião de 180 alunos de terceiro, quarto e quinto anos de quatro faculdades de odontologia do estado de São Paulo, duas particulares e duas públicas, a respeito do papel do professor no processo de ensino-aprendizagem. Um dos fatores considerado fundamental na aprendizagem foi o relacionamento professor-aluno. O professor, dependendo de suas atitudes, pode ser responsável tanto pelo interesse como pelo total desinteresse dos alunos. Esse autores constataram que o professor tem um papel de fundamental importância no aprendizado dos alunos. E verificaram que a maioria dos alunos (80\%) atribui aos professores grande responsabilidade pela sua aprendizagem.

\section{Conteúdos Curriculares e Imagem-Objetivo da Profissão}

O ensino de graduação em odontologia pode ser compreendido como um sistema formador de profissionais para o mercado de trabalho, que se caracteriza pelo tecnicismo, especialização e alienação em relação aos demais fatos presentes na sociedade (Moysés, 2004). Essa idéia confirma-se nos discursos dos alunos:

O aluno, hoje em dia, mesmo durante a faculdade, já acaba escolhendo o curso que ele vai ser especialista. (A5)

Os alunos saem preparados [da faculdade], mas sem preparo pra abrir um consultório. Quanto vai pagar pra sua secretária, quais os encargos sociais que tá pagando (...), a parte de marketing. Como gerenciar seu consultório? Então tudo isso achei falho durante o aprendizado. (A1)

(...) Todos os professores têm que se atualizar, apresentar um caso clínico toda a semana, discutir o que tá acontecendo, o que mais poderia ser feito. Eu acho que isso seria o mais importante. E estimularia os alunos a se formarem com aquele senso do que é melhor o que pode acontecer, quais as possibilidades. Agora a gente já vai se formar aqui sabendo o arroz com fei- 
jão. Igual um colega me disse: a gente se forma pra ser um profissional popular. Os professores não fazem nem menção de mostrar numa aula com profundidade o que tá na moda hoje, o que, por exemplo, a elite usa. Então a gente devia ser mais, se formar pra saber mais coisa, a gente tá se formando sabendo pouco eu acho. (A4)

Acho que tanto a escola pública quanto a particular o nível tá decaindo bastante, o interesse do aluno tá bem menor tanto pra formação profissional quanto pra formação política, os alunos estão bem alienados. (A1o)

Percebe-se pelos depoimentos que quanto aos conteúdos curriculares e a imagem-objetivo da profissão os entrevistados têm uma visão de prática profissional especializada, do mercado de trabalho como profissão liberal, de uma futura prática profissional elitista, evidenciando a alienação do currículo em relação à sociedade.

A literatura científica também tem apontado essas características, como observa-se em Lemos (2005), Masetto (1998), Moysés (2004) e Pizatto et al. (2004).

No Brasil o ensino médico-odontológico é definido por relações externas ao processo pedagógico; é resultado de um modelo vinculado aos componentes econômicos, políticos e ideológicos. De acordo com Chauí (2001) apud Lemos (2005), a universidade está estruturada sobre o modelo da grande empresa capitalista, em que se tem o rendimento como objetivo, a burocracia como meio e as leis do mercado como condição; exatamente como em uma empresa, a universidade está encarregada de produzir incompetentes sociais, presas fáceis de dominação.

O projeto pedagógico hegemônico para o ensino odontológico é fundamentado no modelo flexneriano, baseado no paradigma cartesiano disjuntivo aplicado ao pensamento e a ação, com a separação do todo em partes. Esse modelo, segundo Moysés (2004), enfatiza o domínio cognitivo e instrumental, privilegiando o mecanicismo, o biologicismo, a assistência individual, a especialização precoce, a tecnificação do ato odontológico, ou seja, enfatiza a odontologia curativa.

Nesse contexto, a prática odontológica é elitista e se desvincula da realidade social do país, resultando em um padrão de saúde bucal caótico, apesar da grande quantidade de mão-de-obra presente no mercado.
Brustolin e col. (2006) aplicaram um questionário a 214 acadêmicos de odontologia para traçar o perfil do graduando da Faculdade de Odontologia da Universidade do Planalto Catarinense (Uniplac), principalmente quanto às suas razões para a escolha do curso e suas expectativas em relação à futura profissão. Quanto ao motivo de escolha do curso, os autores observaram que a maioria dos acadêmicos relatou ter escolhido a odontologia principalmente pela realização profissional e pessoal, seguida por segurança e tranqüilidade no futuro, posição social e conforto financeiro e interesse em atuar na comunidade. Observaram ainda que o serviço público tornou-se apenas um trampolim para o recém-graduado que, mesmo diante da atual crise no mercado de trabalho no setor privado, despreza o serviço público odontológico. 0 alto percentual de acadêmicos que pretendem se especializar (98,1\%), assim como a definição prematura pela área verificada neste estudo, confirmou a tendência da expansão da especialização observada nos últimos anos no Brasil.

A formação de indivíduos competentes tecnicamente para o mercado de trabalho se deve ao fato de o planejamento de ensino atual ser feito com base no conteúdo da matéria e não com base na transformação e no crescimento do aluno e na satisfação das necessidades da sociedade. Deve-se também ao fato de o planejamento ser feito sem se realizar levantamentos e pesquisas sobre as exigências atuais e futuras do mercado de trabalho e da transformação da sociedade e sem se estabelecer projeções e previsões sobre as necessidades mais amplas da comunidade (Bordenave e Pereira, 2002). Conseqüentemente, o profissional egresso deixa de ter uma formação generalista, humanista, crítica e reflexiva, para atuar em todos os níveis de atenção à saúde, dirigindo sua atuação para a transformação da realidade em benefício da sociedade, como preconizam as DCN (Brasil, 2002).

Para comparação, pode-se citar o caso do curso de odontologia da Universidade Estadual de Maringá (UEM), baseado no currículo integrado, que permite maior flexibilidade curricular e adaptação a novas necessidades, evita repetições desnecessárias, dicotomias, superposições, dando ao aluno uma visão mais global e mais holística, enfatizando a formação humanítica cultural e a integração multiprofissional. 0 currículo integrado procura formar recursos huma- 
nos, levando em conta o contexto socioeconômico, cultural e político da região e do país, a situação epidemiológica, a realidade dos serviços de saúde e do exercício profissional (Conrado e col., 2004). 0 perfil profissional que esse curso forma refere-se a um ser integral e integrado no contexto da saúde e da sociedade, atento às realidades sociais e ao mercado de trabalho. 0 curso de odontologia da UEM vem cumprindo antecipadamente, desde 1992, o que há de essencial na LDB bem antes da sua promulgação, em 1996, e nas diretrizes curriculares nacionais, anterior à sua implantação (Hidalgo e Conrado, 2004).

No curso de odontologia da UEM os acadêmicos relatam que o enfoque voltado para o serviço público é grande. Isso mostra que a formação propiciada pelo currículo integrado possibilita aos egressos uma forma de pensar a saúde bucal com enfoque generalista e com ênfase na visão de saúde bucal coletiva (Tanaka e Amaral, 2004).

\section{Estratégias de Ensino-Aprendizagem}

Para as estratégias de ensino-aprendizagem a organização curricular voltada à formação de profissionais para o mercado de trabalho traz como conseqüência a ênfase na transmissão oral de conhecimentos, na maioria das vezes ilustrada com quadro negro e giz, projeção de slides e multimídia. Nessa concepção, primeiro o aluno adquire conhecimentos para depois aplicá-los na prática, o professor é o centro maior das informações a serem transmitidas e há um grande número de alunos em sala, o que promove o emprego da exposição. Isso se confirma nos relatos de alguns alunos entrevistados:

Utilizavam projetor de slides, às vezes, data show, ou então tinha professor que entregava folha pra gente ir acompanhando esquemas que ele ia falando, ou às vezes, ele escrevia na lousa. (A9)

Geralmente no nosso ensino cada disciplina tem um certo protocolo. Começa com aula teórica onde você recebe uma teoria de uma seqüência de trabalho, em tópicos, você aprende isso e põe em prática isso na clínica. (A5)

Quando você chega na clínica, sai da sala de aula e vai pra clínica, você não sabe muito bem, porque não conseguiu acompanhar a disciplina (...). (A3)

Tem muitas disciplinas que têm dois, três professores pra cuidar de sessenta alunos, isso não dá. (A5)
Essas características de estratégias de ensinoaprendizagem também foram identificadas por Cunha e Leite (1996), Lemos (2005), Masetto (1998), Raldi e col. (2003) e Secco e Pereira (2004).

Nesses relatos fica evidente a presença da abordagem tradicional com uma grande ênfase no processo de ensino, centrado no professor, o qual aparece como agente principal e responsável pelo ensino. Torna-se evidente também que o curso de graduação em odontologia da UEL não prioriza estratégias ativas de ensino-aprendizagem que tornem o aluno sujeito da aprendizagem e o professor facilitador desse processo.

De acordo com Lopes (1993), a utilização da aula expositiva na sala de aula aparece desde o plano pedagógico dos jesuítas, considerado como o marco inicial do ideário pedagógico nacional, até os mais recentes livros de didática. A aula expositiva é conceituada como comunicação verbal estruturada, utilizada pelos professores com o objetivo de transmitir determinados conteúdos aos alunos. A exposição apresenta algumas vantagens: economiza tempo e ajuda na compreensão de assuntos complexos, porém apresenta algumas limitações: a ênfase na comunicação verbal, o autoritarismo do professor e a inibição da participação do aluno.

Na estratégia de ensino-aprendizagem tradicional, segundo Bordenave (1983), as idéias e os conhecimentos são os pontos mais importantes da educação e, como conseqüência disso, a experiência fundamental que o aluno deve viver para alcançar seus objetivos é a de receber o que o professor lhe oferece, levando-o à memorização e à passividade. Além disso, predomina a distância entre teoria e prática, tendência ao racionalismo radical, preferência pela especulação teórica, falta de problematização da realidade.

\section{Avaliação}

Os entrevistados citaram a avaliação como elemento de pressão e de cobrança do conteúdo transmitido, por meio de provas tradicionais e de avaliação prática. No entanto, ressaltaram que ela lhes estimulam a busca de informações:

A avaliação não acho que influenciou muito na minha aprendizagem. Eu acho que serviu mais como uma maneira pra você ter que estudar a matéria porque ela vaiser cobrada de você então, você tem que estudar. (A6) 
A grande maioria foi uma avaliação prática (...) provas escritas, provas teóricas, provas alternativas. (A8) Eu acho certo a avaliação porque $99 \%$ dos alunos estudam na última hora, e ele não vai estudar se não tiver prova. (A5)

(...) A avaliação é o que desperta o estopim pra você ter que começar a correr atrás de livros, você ter algum contato com livros. (A6)

A prática avaliativa tem sido discutida na literatura por Bordenave e Pereira (2002), Brasil (2003), Cunha e Leite (1996) e Hoffmann (1993).

Tanto professores quanto alunos concebem a avaliação como uma prática de registro de resultados acerca do desempenho do aluno em um determinado período do ano letivo. Considerar a avaliação reduzida a uma dimensão de procedimento terminal, dissociada da ação educativa, limita o aprofundamento necessário em relação ao significado das interferências constantes dos professores nas manifestações dos alunos, resumindo-se a avaliação à questão de aprovação ou reprovação. A avaliação concebida como julgamento de resultados pré-determinados baseia-se na autoridade e respeito unilaterais - do professor, e limitam o desenvolvimento da autonomia moral e intelectual do aluno, desconsiderando a importância da reciprocidade na ação educativa (Hoffmann, 1993).

A avaliação compreende o estabelecimento de objetivos pelo professor que, na maioria das vezes, estão relacionados estreitamente a itens de conteúdo programático e a determinados intervalos, a verificação por meio de testes, do alcance desses objetivos pelos alunos (Bordenave e Pereira, 2002; Brasil, 2003).

Alguns alunos entrevistados relataram que as provas cobram um aprendizado pela retenção de conceitos, ou seja, exigem memorização e reprodução de dados. A avaliação, assim, assume a função comparativa e classificatória, em que a produção e o registro de notas e/ou conceitos classificam o aluno, promovendo-o ou não para a série seguinte. No entanto, a simples retenção da informação, sem raciocínio crítico, sem clareza de sua aplicação, sem correlação com outros acontecimentos não significa aprendizagem e tende a ser transitória e rapidamente esquecida. Essa idéia se confirma no seguinte relato:

Nessa avaliação sobre pressão que é uma prova que você estuda dois dias antes, se mata de estudar. Isso não traz muita ajuda pra gente, que depois vai tudo pro espaço, no outro dia já não lembra mais nada. (A1o)

Desse modo, a avaliação deixa de cumprir o seu papel, que é o de movimento de transformação, e conseqüentemente impede o processo de crescimento para a liberdade e a autonomia e para o processo de conhecimento do aluno (Luckesi, 1992). Demo (2005) também destaca a cobrança do aprendizado pela retenção de conceito.

Segundo Miguel (2004), a avaliação de estudantes de saúde limita-se a identificar a capacidade de o aluno executar tarefas ou reconhecer uma condição clínica presente no paciente, seguindo uma lista de procedimentos técnicos, que devem ser executados, conseqüentemente tem-se a insegurança do recém-formado, estimulando a sua especialização precoce.

\section{Considerações Finais}

Este estudo revela que a formação de cirurgiões-dentistas possivelmente não ocorre com forte embasamento generalista, humanista, crítico e reflexivo. Indica que os cursos de odontologia não se liberaram de práticas ditadas pelo mercado profissional liberal.

Com a consolidação do Sistema Único de Saúde (SUS) e principalmente com a expansão do Programa Saúde da Família (PSF), que é um programa importante na área de saúde bucal, é bastante provável que as IES tenham de repensar os seus currículos para formar profissionais que atendam às necessidades socioeconômicas do país, melhorando, assim, os índices de saúde. Para isso, a construção do projeto pedagógico deve se voltar aos problemas advindos das interações que se estabelecem entre as IES, os governos e a sociedade.

Deve-se buscar estabelecer uma nova relação entre professor-aluno, em que o docente seja capaz de refletir sobre sua importância na aprendizagem dos alunos, procurando, assim, caminhos alternativos, que tornem o aluno o sujeito da aprendizagem e o professor o facilitador e o mediador do processo ensino-aprendizagem.

Cabe também ao docente estimular a capacidade do aluno que Delors (2001) caracteriza como aprender a conhecer e aprender a fazer (grifo nosso), tornando o aluno capaz de buscar os conhecimentos necessários a sua atualização e colocar em prática os 
seus conhecimentos, mostrando a responsabilidade pela educação permanente e o espírito crítico, conforme preconizam as DCN. Assim, compete ao professor utilizar a avaliação baseada na educação democrática, em uma perspectiva de inclusão do educando no processo educativo, e não de exclusão; a participação e a solidariedade; a contribuição para que o educando se torne o sujeito do seu processo de aprendizagem; e, o processo e o resultado qualitativo do aprendizado.

Por sua vez, as IES precisam estar conscientes da importância do professor no processo ensino-aprendizagem, propiciando a ele condições de trabalho, como subsidiar cursos de capacitação didático-pedagógica, para que ele possa ensinar o aluno a pensar e formar cidadãos que questionem a realidade e busquem soluções originais e criativas, além de proporcionar a abertura para novas possibilidades de estratégias ativas de ensino-aprendizagem.

Transformar o processo de educação de cirurgiõesdentistas é complexo e dinâmico e requer mudanças nas concepções de saúde e educação e suas práticas, nas relações entre cirurgiões-dentistas e população, entre cirurgiões-dentistas e demais profissionais de saúde, entre docentes e discentes.

\section{Referências}

BARDIN, L. Análise de conteúdo. Lisboa: Edições 7o, 1977.

BORDENAVE, J. E. D. Alguns fatores pedagógicos. In: . A capacitação pedagógica do programa de

formação de pessoal de nível médio em saúde. Tradução M. T. Grandi. Brasília, DF: OPAS, 1983. Disponível em: <www.opas.org.br/rh/publicacoes/ textos_apoio/ pubo6CPT1.pdf $>$. Acesso em: 3 ago. 2005 .

BORDENAVE, J. D.; PEREIRA, A. M. Estratégias de ensino-aprendizagem. 24. ed. Petrópolis: Vozes, 2002.

BOTAZZO, C. Da arte dentária. São Paulo: Hucitec: Fapesp, 2000.

BRASIL. Ministério da Educação e do Desporto. Parecer $n^{\circ}$ CNE/CES 776/97, de 3 de dezembro de 1997. Orientações para as diretrizes curriculares do curso de graduação. Disponível em: <http:// portal.mec.gov.br/cne/arquivos/pdf/PCS77697.pdf >. Acesso em: 5 nov. 2005.
BRASIL. Ministério da Educação e Cultura. Conselho Nacional de Educação. Resolução CNE/CES no 3 / 2002. Institui as diretrizes curriculares nacionais do curso de graduação em Odontologia. Diário Oficial da União, Brasília, DF, 4 mar. 2002. Seção 1, p. 10.

BRASIL. Ministério da Saúde. Secretaria de Gestão de Investimentos em Saúde. Projeto de profissionalização dos trabalhadores da área de enfermagem. Fundação Oswaldo Cruz. Formação pedagógica em educação profissional na área de saúde: enfermagem: núcleo estrutural: proposta pedagógica: avaliando a ação 8. 2 ed.. Brasília, DF, 2003.

BRUSTOLIN, J. et al. Perfil do acadêmico de odontologia da Universidade do Planalto Catarinense - Lages - SC, Brasil. Revista da ABENO, Brasília, DF, v. 6, n. 1, p. 70-76, jan./jun. 2006. Disponível em: <http://www.abeno.org.br>. Acesso em: 5 jun. 2006.

CARVALHO, A. C. P. Educação e saúde em odontologia: ensino da prática e prática do ensino. São Paulo: Santos, 1995.

CARVALHO, A. C. P. Projeto pedagógico. In: REUNIÃO DA ASSOCIAÇÃO BRASILEIRA DE ENSINO ODONTOLÓGICO, 33.; ENCONTRO NACIONAL DE DIRIGENTES DAS FACULDADES DE ODONTOLOGIA, 24., 1998, Fortaleza. Anais... Fortaleza, 1998. p. 27-42.

CASTANHO, M. E. Professores de ensino superior da área da saúde e sua prática pedagógica. Interface Comunicação, Saúde, Educação, Botucatu, v. 6, n. 10, p. 51-62, fev. 2002. Disponível em: <http:// www.interface.org.br>. Acesso em: 1 maio 2005.

CHAVES, M. M. Odontologia social. 3. ed. São Paulo: Artes Médicas, 1986.

CONRADO, C. A.; GOMES, G. S.; ROBAZZA, C. R. C. O projeto pedagógico: estruturação e desenvolvimento curriculares - o currículo multidisciplinar integrado. In: TERADA, R. S. S.; NAKAMA, L. (Org.). A implantação das Diretrizes Curriculares Nacionais de Odontologia: a experiência de Maringá. São Paulo: Hucitec, 2004. p. 23-49.

CUNHA, M. I.; LEITE, D. B. C. Decisões pedagógicas e estruturas de poder na universidade. Campinas: Papirus, 1996. 
DELORS, J. Educação: um tesouro a descobrir. 6. ed. São Paulo: Cortez; Brasília, DF: Unesco, 2001.

DEMO, P. Saber pensar. Revista da ABENO, Brasília, DF, v. 5, n. 1, p. 75-79, jan./jun. 2005. Disponível em: <http://www.abeno.org.br>. Acesso em: 10 abr. 2005.

FEUERWERKER, L. C. M. Educação dos profissionais de saúde hoje: problemas, desafios, perspectivas e as propostas do Ministério da Saúde. Revista da ABENO, Brasília, DF, v. 3, n. 1, p. 24-27, jan./dez. 2003. Disponível em: <http://www.abeno.org.br>. Acesso em: 22 jun. 2004 .

FRASER, D. QSR NVivo: reference guide. 3. ed. Melbourne: QSR International, 2000.

FREITAS, S. F. T.; KOVALESKI, D. F.; BOING, A. F. Desenvolvimento moral em formandos de um curso de odontologia: uma avaliação construtivista.

Ciência \& Saúde Coletiva, Rio de Janeiro, v. 10, n. 2, p. 453-462, abr./jun. 2005.

HIDALGO, M. M.; CONRADO, C. A. Particularidades do projeto pedagógico. In: TERADA, R. S. S.; NAKAMA, L. (Org.). A implantação das Diretrizes Curriculares Nacionais de Odontologia: a experiência de Maringá. São Paulo: Hucitec, 2004. p. 51-68.

HOFFMANN, J. Avaliação: mito e desafio. 12. ed. Porto Alegre: Educação \& Realidade, 1993.

LAZZARIN, H. C. O papel do professor no processo ensino-aprendizagem: percepção de professores e alunos de odontologia. 2005. Dissertação (Mestrado em Saúde Coletiva) - Departamento de Saúde Coletiva, Universidade Estadual de Londrina, Londrina, 2005.

LEMOS, C. L. S. A implantação das Diretrizes Curriculares dos Cursos de Graduação em Odontologia no Brasil: algumas reflexões. Revista da ABENO, Brasília, DF, v. 5, n. 1, p. 8o-85, jan./jun. 2005. Disponível em: 〈http://www.abeno.org.br >. Acesso em: 10 abr. 2005.

LIBÂNEO, J. C. Tendências pedagógicas na prática escolar. In: LUCKESI, C. C. Filosofia da educação. São Paulo: Cortez, 1992. p. 53-75.
LOPES, A. O. Aula expositiva: superando o tradicional. In: VEIGA, I. P. A. (Org.). Técnicas de ensino: por que não? 2. ed. Campinas: Papirus, 1993. p. 35-113.

LUCKESI, C. C. Filosofia da educação. São Paulo: Cortez, 1992.

LÜDKE, M; ANDRÉ, M. E. D. A. Pesquisa em educação: abordagens qualitativas. São Paulo: EPU, 1986.

MASETTO, M. T. Processo de aprendizagem no ensino superior e suas conseqüências para a docência universitária. In: REUNIÃO DA ASSOCIAÇÃO BRASILEIRA DE ENSINO ODONTOLÓGICO, 33.; ENCONTRO NACIONAL DE DIRIGENTES DAS FACULDADES DE ODONTOLOGIA, 24., 1998, Fortaleza. Anais... Fortaleza, 1998. p. 9-16.

MIGUEL, J. C. A avaliação. In: TERADA, R. S. S.; NAKAMA, L. (Org.). A implantação das Diretrizes Curriculares Nacionais de Odontologia: a experiência de Maringá. São Paulo: Hucitec, 2004. p. 129-138.

MINAYO, M. C. S. O desafio do conhecimento: pesquisa qualitativa em saúde. 3 ed. São Paulo: Hucitec, 1994.

MOYSÉS, S. J. Políticas de saúde e formação de recursos humanos em odontologia. Revista da ABENO, Brasília, DF, v. 4, n. 1, p. 30-37, 2004. Disponível em: <http://www.abeno.org.br>. Acesso em: 31 out. 2004 .

NARVAI, P. C. Saúde bucal coletiva: um conceito. Odontologia e Sociedade, São Paulo, v. 3, n. 1/2, p. 47$52,2001$.

PIZZATTO, E. et al. O papel do professor no ensino odontológico. Saúde em Debate, Rio de Janeiro, v. 28, n. 66, p. 52-57, jan./abr. 2004

RALDI, D. P. et al. O papel do professor no contexto educacional sob o ponto de vista dos alunos. Revista da ABENO, Brasília, DF, v. 3, n. 1, p. 15-23, 2003. Disponível em: <http://www.abeno.org.br>. Acesso em: 20 jun. 2004 . 
REGO, A. O bom cidadão docente universitário na senda da qualidade no ensino superior. Educação \& Sociedade, Campinas, v. 22, n. 75, p. 174-199, ago. 2001. Disponível em: <http://

www.cedes.gw.unicamp.br/revista/rev/rev75.html>. Acesso em: 5 dez. 2004.

SECCO, L. G.; PEREIRA, M. L. T. Concepções de qualidade de ensino dos coordenadores de graduação: uma análise dos cursos de odontologia do Estado de São Paulo. Interface - Comunicação, Saúde, Educação, Botucatu, v. 8. n. 15, p. 313-330, mar./ago. 2004. Disponível em: <http:// www.interface.org.br>. Acesso em: 30 abr. 2005.
TANAKA, F.; AMARAL, M. A. A formação de profissionais de saúde e a experiência de Maringá. In: TERADA, R. S. S.; NAKAMA, L. (Org.). A implantação das Diretrizes Curriculares Nacionais de Odontologia: a experiência de Maringá. São Paulo: Hucitec, 2004. p. 139-147.

TURATO, E. R. Decidindo quais indivíduos estudar. In: Tratado da metodologia da pesquisa clínico-qualitativa: construção teóricoepistemológica, discussão comparada e aplicação nas áreas da saúde e humanas. 2. ed. Petrópolis: Vozes, 2003. p. 351-368. 